\title{
Política pública de regulação da educação superior brasileira: análise documental do decreto 9.235/2017
}

\author{
Eric Ferdinando Kanai Passone ${ }^{1}$ \\ Orcid: https://orcid.org/0000-0002-0305-6734 \\ Marcos Machado ${ }^{2}$ \\ Orcid: https://orcid.org/0000-0003-0043-7459
}

\begin{abstract}
Resumo
Este artigo aborda a política pública da educação superior brasileira, com foco na normatização da regulação e supervisão dos cursos de graduação. Assim, o objetivo deste estudo foi identificar e analisar o arcabouço sociojurídico da educação superior que orienta a regulação, a supervisão e a avaliação das Instituições de Educação Superior (IES) no Brasil. Realizou-se uma pesquisa de caráter exploratório e qualitativo, utilizando-se dos recursos de revisão bibliográfica sobre o tema bem como da técnica de análise documental sistematizada do Decreto $\mathrm{n}^{\circ}$ 9.235, de 15 de dezembro de 2017, que dispõe sobre o exercício das funções de regulação, supervisão e avaliação das Instituições de Educação Superior e dos cursos superiores de graduação no Sistema Federal de Ensino. O desenvolvimento desta pesquisa possibilitou identificar a regulação, como instrumento de gestão empregado na investigação, monitoramento e diagnóstico da educação superior.
\end{abstract}

Palavras-chave: Políticas públicas de educação. Educação Superior. Regulação.

\begin{abstract}
This article addresses the public policy of Brazilian higher education, focusing on the regulation of the regulation and supervision of undergraduate courses. Thus, the objective of this study was to identify and analyze the socio-legal framework of higher education that guides the regulation, supervision and evaluation of Higher Education Institutions (HEIs) in Brazil. An exploratory and qualitative research was carried out, using the bibliographic review resources on the theme as well as the systematic document analysis technique of Decree No. 9,235, of December 15, 2017, which provides for the exercise of the functions of regulation, supervision and evaluation of Higher Education Institutions and higher graduation courses in the Federal Education System. The development of this research made it possible to identify regulation, as a management tool used in the investigation, monitoring and diagnosis of higher education.
\end{abstract}

Keywords: Public education policies. Higher education. Regulation.

\footnotetext{
${ }^{1}$ Pós-doutorado em Educação pela USP. Doutor em Educação pela Unicamp. Docente do Programa de Pósgraduação em Educação da Universidade Cidade de São Paulo, São Paulo/SP, Brasil. E-mail: eric.passone@unicid.edu.br

${ }^{2}$ Mestre em Formação de Gestores. Coordenador do curso de direito e docente na Associação Educacional Dom Bosco. E-mail: marcosmachado001@hotmail.com
} 


\section{Introdução}

A presente pesquisa se inscreve no campo de estudos das políticas públicas de Educação Superior no Brasil, tendo como escopo a normatização da regulação dos cursos de graduação, e trata dos aspectos da autorização, reconhecimento e renovação de credenciamento, considerando que tais atos regulatórios estão relacionados com a concessão de abertura e continuidade dos cursos ofertados pelas Instituições de Ensino Superior (IES) no país.

O Estado brasileiro, por meio da Constituição da República Federativa do Brasil (CRFB) promulgada em 5 de outubro de 1988, também conhecida como Carta Cidadã, reconhece, em seu artigo 205, que a educação é direito de todos e dever do Estado e da família. A partir do texto constituinte, ensejou-se a edição da nova Lei de Diretrizes e Bases da Educação Nacional (LDBEN), Lei n ${ }^{\circ}$ 9.394, de 20 de dezembro de 1996, que organiza a educação brasileira em dois níveis de ensino, a saber: a educação básica e a educação superior.

Em sentido lato, a Educação Superior está associada à ideia genérica e moderna de aquisição e produção de conhecimentos, implicando-a ao compromisso de "[...] reconstrução permanente do conhecimento e sobretudo de sua humanização", além de suas finalidades previstas em lei (DEMO, 1997, p. 76).

A LDBEN preconiza, em seu artigo 43, incisos I ao VII, uma Educação Superior que estimule: a criação cultural, o espírito científico e o pensamento reflexivo; a formação de quadros profissionais qualificados para o desenvolvimento da sociedade; a pesquisa, a investigação científica e o desenvolvimento tecnológico, de modo a "desenvolver o entendimento do homem e do meio em que vive"; a divulgação e a comunicação de conhecimentos que representam o patrimônio humano; o desejo permanente de aperfeiçoamento profissional e cultural; o conhecimento dos problemas concretos do mundo e a prestação de serviços à comunidade; e estimula a extensão e a participação da sociedade, de modo a socializar as descobertas e os benefícios "[...] da criação cultural, da pesquisa científica e tecnológica", engendrados nas IES (BRASIL, 2014, p. 28).

É importante mencionar que grande parte do que se encontra na nova LDBEN sobre a Educação Superior resultou de duas leis que se encontravam em vigor, a saber: a Lei $\mathrm{n}^{\mathrm{o}}$ 5.540, de 28 de novembro de 1968, também conhecida como "reforma universitária", e seu complemento, o Decreto-Lei $\mathrm{n}^{\circ}$ 464, de 11 de fevereiro de 1969. A especificidade desses textos de lei em relação à Educação Superior, em termos de estrutura e funcionamento, deve-se ao destacamento que representaram em relação à primeira LDBEN (Lei $\mathrm{n}^{\circ} 4.024$, de 20 de dezembro de 1961). Tal condição suplementar dessas legislações foi suprimida com o texto de lei redigido por Darcy Ribeiro na nova LDBEN, que introduziu os 15 artigos que definem a organização, o funcionamento e a regulação, quanto ao que se refere à Educação Superior no país.

Souza e Silva (2001) destacam que, mesmo que alguns aspectos referentes ao conteúdo legal tenham mudado de maneira significativa, outros revelam certas continuidades nas suas proposições, tais como os objetivos e/ou finalidades da Educação Superior, a produção e divulgação do conhecimento, a integração entre ensino, pesquisa e extensão, além da busca pela autonomia da universidade (Lei $n^{\circ} 5.540 / 1968$, artigo $3^{\circ}$; Lei no 9.394/1996, artigo 53).

Mesmo sem adentrar nas motivações históricas e nas demandas estudantis que culminaram na reforma universitária de 1968, pois extrapolaria o escopo deste artigo, ainda é notório destacar o paradoxo que, no âmbito da ideia do nacional-desenvolvimentismo do período político conhecido pelo autoritarismo militar, a Lei $\mathrm{n}^{\circ} 5.540 / 1968$ tivesse como objetivo "[...] garantir a eficiência, modernização e flexibilidade administrativa da Universidade 
Brasileira [...]", considerando-se a "[...] formação de recursos humanos de alto nível para o desenvolvimento do país" (FÁVERO, 2006, p. 32).

No entanto, contrariamente, a lei da reforma universitária acabaria por disciplinar e enrijecer o funcionamento e a capacidade das instituições universitárias de "decidir sobre sua organização, seus cursos, seu pessoal e seus interesses". Os avanços introduzidos com a LDBEN de 1996 se caracterizam pelo "tom democrático de suas proposições", o que possibilitou "liberar" o funcionamento dos órgãos acadêmicos e das estruturas administrativas, mas não sem o ônus de novas regulamentações atinentes ao processo de autorização e de reconhecimento de cursos e instituições e de novas responsabilidades decorrentes de transformações quanto ao papel do Estado, em que se destacou, por exemplo, a função de regulação do processo de avaliação:

[...] obrigando-as a qualificar-se perante as novas exigências da sociedade em mudança [...]. O tom democrático dessas proposições pode ser exemplificado pela crescente indistinção entre a natureza pública e privada das instituições: são todas tratadas em pé de igualdade, ressalvado o compromisso de ambas em relação à lei e à qualidade de seus serviços. (SOUZA; SILVA, 2001, p. 91).

Nesse sentido, compreende-se como as IES têm respondido às novas exigências de formação profissional de quadros altamente qualificados e à demanda do mercado de trabalho cada vez mais competitivo, considerando-se os avanços e as necessidades de transformações da realidade da educação e dos novos cenários e contextos do mundo do trabalho, que, por sua vez, refletem as mudanças políticas e socioeconômicas globais, as quais, em certa medida, condicionam as políticas educacionais em nível mundial, regional e local.

De acordo com a LDBEN de 1996, a Educação Superior se caracteriza conforme o tipo de vínculo da IES junto ao sistema federal, estadual e municipal. No artigo 16, encontra-se o aparato legal para o Sistema Federal de Ensino (SFE), compreendendo as instituições que são mantidas pelo poder público e pelo setor privado e os órgãos federais de educação. As IES são submetidas às leis e regulamentações do poder público, como a criação, autorização e reconhecimento de cursos e o credenciamento e recredenciamento da IES perante as normas do Ministério da Educação (MEC) (SAVIANI, 2003).

Tanto as IES públicas como as IES de iniciativa privada estão subordinadas às exigências legais para efeito de autorização e reconhecimento de cursos, bem como o credenciamento de IES, sujeitando-se à periodicidade de funcionamento (oferta de cursos), com prazos limitados, podendo ser renovadas as respectivas autorizações, desde que sejam submetidas ao processo regular de avaliação.

As IES estaduais e municipais estão vinculadas aos sistemas estaduais e municipais de ensino e se submetem às regras do Conselho Estadual de Educação (CEE) para obter os recursos públicos federais, como bolsas de pesquisa (NEVES, 2012). As IES privadas são instituições particulares de ensino com fins lucrativos; muitas delas foram fundadas por proprietários ou mantenedoras que têm sua origem e formação vinculadas ao campo empresarial ou político. Existem ainda as instituições educacionais sem fins lucrativos e beneficentes, as chamadas filantrópicas, de utilidade pública, que aplicam os resultados operacionais de forma integral na manutenção e desenvolvimento de seus objetivos (DAVIS, 2002).

Em referência à participação da iniciativa privada no campo universitário, um dos requisitos acrescentados pela LDBEN de 1996 foi a capacidade de autofinanciamento das IES privadas, revelando uma forma de atuação do Estado, que passou a realizar um papel mais direto de regulador, de acordo com o parágrafo $1^{\circ}$ do artigo $8^{\mathrm{a}}$ da lei: " $\S 1^{\mathrm{o}}$. Caberá à União a coordenação da política nacional de educação, articulando os diferentes níveis e 
sistemas e exercendo função normativa, redistributiva e supletiva em relação às demais instâncias educacionais" (BRASIL, 1996).

Santos $(2019$, p. 124) estabelece que a "[...] década de 1990 foi considerada o auge do quase-mercado da educação superior", enquanto Carneiro e Novaes (2008) apontam que, na década de 1990, a política implementada pelo Estado restabeleceu a tendência de expansão da iniciativa privada motivada inicialmente pela Constituição Federal de 1988 e posteriormente pela promulgação da LDBEN de 1996. Em pesquisa, Mancebo e colaboradores $(2018$, p. 8) confirmam tal procedimento até a atualidade, pois, segundo os autores, o Estado: "[...] tem alterado leis, decretos, portarias e resoluções, dando maior liberdade de atuação às empresas privadas que atuam no campo da educação, além de buscar favorecer o acesso aos recursos do fundo público, por meio, por exemplo, do FIES (Fundo de Financiamento Estudantil) e do PROUNI (Programa Universidade para Todos)".

Tendo em vista que a Educação Superior está disciplinada por leis e atos normativos expedidos pelo poder público e considerando-se ainda que a função dos administradores acadêmicos exige o conhecimento dessa legislação, o presente apresenta uma análise documental sistemática do Decreto $\mathrm{n}^{\circ}$ 9.235/2017, que dispõe sobre o exercício das funções de regulação, supervisão e avaliação das IES e dos cursos superiores de graduação no SFE. Trata-se, portanto, de um estudo qualitativo e exploratório, utilizando-se das técnicas de pesquisa documental e levantamento bibliográfico. A pesquisa documental possibilita o tratamento de documentos que não passaram por tratamento analítico, ou mesmo que possam ser analisados de acordo com o objetivo da. Nesse sentido, a presente pesquisa realizou uma análise documental acerca do Decreto $\mathrm{n}^{\circ}$ 9.235/2017, que trata exclusivamente da questão da regulação da Educação Superior no SFE como objeto de estudo, o que permitiu sistematizar e conhecer as minúcias desse decreto. Conforme Cellard (2012), um documento é uma fonte de informação estática e datada historicamente, mas as análises e interpretações são mediadas pela percepção de cada pesquisador e relacionadas à dimensão teórica que fundamenta sua pesquisa.

\section{Cenário recente das políticas públicas da educação superior}

A década de 1990 foi marcada pela reforma administrativa do Estado, pela incorporação de dispositivos da nova gestão pública e pelos novos modelos de regulação de políticas públicas educacionais (PASSONE, 2014; 2013). Os principais marcos basilares de debate contemporâneo sobre Educação Superior abarcam grandes questões evidenciadas na literatura como pares conceituais dialéticos, a saber: acesso e equidade; qualidade e massificação; democratização e privatização; seletividade e diferenciação/diversidade (DIAS SOBRINHO, 2010; SGUISSARDI, 2013).

Após a promulgação da Carta Cidadã, a reforma educacional conduzida durante a reconhecida "era FHC" substituiu as legislações anteriores, como a Lei $n^{\circ}$ 4.024/1961, que tratava da primeira LDBEN, e a Lei $\mathrm{n}^{\circ} 5.540 / 1968$, que fixava a organização e funcionamento do Ensino Superior. Concomitantemente nesse período foi elaborado o Plano Nacional de Educação - PNE (Lei n ${ }^{\circ} 10.172 / 2001$ ), medida prevista no artigo 214 da Carta Cidadã e no artigo 87 da nova LDBEN.

Com a nova edição do PNE (Lei $n^{0} 13.005 / 2014$ ), com relação à Educação Superior, coube às metas 12 e 13 tratarem do assunto, sendo que à meta 12, juntamente com as estratégias, foi consignado o compromisso de elevar a taxa de matrícula (bruta em $50 \%$ e líquida em 33\%) na Educação Superior, bem como assegurar a qualidade da oferta e expansão no mínimo em $40 \%$ referente às novas matrículas no ensino público. Dentre as estratégias estabelecidas para atingir a meta 12, destacam-se: (I) ampliação das políticas de inclusão e de assistência estudantil dirigidas aos estudantes de instituições públicas, bolsistas de instituições privadas de Educação Superior e beneficiários do Fundo de Financiamento Estudantil (FIES); 
(II) expansão no financiamento estudantil por meio do FIES; (III) ampliação do FIES, de que trata a Lei $\mathrm{n}^{\mathrm{o}}$ 10.260/2001, e do Programa Universidade para Todos (PROUNI), de que trata a Lei $n^{\circ} 11.096 / 2005$.

O governo federal, por meio da meta 13, deveria assumir o compromisso de elevar a qualidade da Educação Superior e ampliar a proporção de mestres e doutores do corpo docente. Para tanto, ressaltam-se: (I) aperfeiçoar o Sistema Nacional de Avaliação da Educação Superior (SINAES), de que trata a Lei $\mathrm{n}^{0}$ 10.861/2004, fortalecendo as ações de avaliação, regulação e supervisão; (II) induzir processo contínuo de autoavaliação das IES, fortalecendo a participação das comissões próprias de avaliação, bem como a aplicação de instrumentos de avaliação que orientem as dimensões a serem fortalecidas, destacando-se a qualificação e a dedicação do corpo docente.

Destaca-se, também, a criação do Conselho Nacional de Educação (CNE), por meio da Lei $n^{\circ}$ 9.131/1995, que substituiu o Conselho Federal de Educação (CFE) previsto na primeira LDBEN (1961). O CFE, responsável pelas autorizações, reconhecimento e credenciamento de cursos e de instituições era "[...] um órgão cobiçado pelos empresários do ensino. [...] os empresários do ensino e seus prepostos, amparados pelas composições políticas da ditadura militar, lograram constituir a maioria, quando não a totalidade desse Conselho" (CUNHA, 2003, p. 47).

No entanto, tais atribuições foram alteradas pela Medida Provisória $\mathrm{n}^{\circ}$ 2.216-37/2001, reduzindo o escopo de seu papel deliberativo para os cursos de Direito e aos da área de Saúde (Medicina, Psicologia e Odontologia), em relação ao credenciamento das instituições que buscavam implementar cursos na área Jurídica e da Saúde, além do credenciamento e do recredenciamento de universidades e centros universitários. Ao Ministério da Educação e da Cultura (MEC) ficou o encargo de deliberar sobre os demais cursos de graduação e sobre o credenciamento e recredenciamento das IES correspondentes.

No âmbito das ações voltadas à Educação Superior, também se destaca a criação do FIES e do Exame Nacional de Cursos, que ficou conhecido como "Provão", por meio da implementação do sistema de avaliação criado em 1996 pelo MEC, que tinha como finalidade monitorar a qualidade do Ensino Superior no país. Pereira e Silva (2010) lembram que, a partir da "era Lula" (2003-2011), as políticas públicas adotadas visaram promover igualdade de oportunidades e inclusão social. Assim, paralelamente à continuidade do FIES, destacamse a criação do PROUNI e o aprimoramento dos mecanismos de avaliação. A Medida Provisória $n^{0} 147 / 2003$, posteriormente convertida na Lei $n^{\circ} 10.861 / 2004$, que instituiu o SINAES, modificou as atribuições da Câmara de Educação Superior, revogando os artigos $3^{\circ}$ e $4^{\circ}$ da Lei $n^{\circ} 9.131 / 1995$.

Ribeiro (2015, p. 159) salienta o problema das funções do SINAES, a saber: “[...] como as IES de pequeno porte constituem a maior parte do Sistema Federal de Ensino Superior, a função regulatória da avaliação termina sobressaindo-se, [...] em detrimento da função educativa". O que deveria ser a primeira preocupação do governo, na realidade, acaba sendo uma demanda de segunda ordem, pois se preocupa em primeiro lugar em estabelecer regras de regulação como se fosse o mais importante. As IES de grande porte privadas, cujos mantenedores são grandes grupos econômicos, mesmo com a imagem abalada por uma eventual avaliação negativa, terão fluxo de caixa suficiente para reverter a sua imagem através da publicidade. Os efeitos de uma avaliação negativa sobre as IES de médio e pequeno porte privadas, normalmente mantidas por famílias ou pequenos grupos empresariais, são muito mais intensos e podem ser devastadores, colocando em risco a própria sobrevivência institucional. E afirma ainda, em suas considerações finais, que o futuro do SINAES dependerá principalmente de como o MEC vai se comportar com a regulação do SFE (RIBEIRO, 2015).

Nesse mesmo sentido, Haas (2017, p. 127) reflete que os critérios inseridos no instrumento de avaliação "[...] são cópias de ideias fragmentadas de outros contextos que 
buscam resultados considerados positivos internacionalmente mais voltados aos compromissos mercantis [...] do que para a formação cidadã e qualificada de que é carente o Brasil", ou seja, ressalta a importância da qualidade do ensino com que o governo deveria se preocupar.

Consequentemente, a avaliação da Educação Superior no Brasil realizada a partir do SINAES, por meio do tripé: avaliação da instituição, avaliação dos cursos e avaliação do desempenho dos estudantes, produz resultados que geram uma nota, um índice, possibilitando a criação de rankings nacionais das IES. É preciso considerar que os resultados são expressos na atribuição de faixas de valor que vão de 1 a 5 . Nesse sentido, os resultados encontrados pela autora "[...] apontam que as políticas de avaliação da educação superior brasileira incorporam recomendações e práticas da regulação transnacional" (HASS, 2017, p. 126).

De outro modo, Santos (2019, p. 135) aponta que o "contexto em que o SINAES surge revela um movimento oriundo do expansionismo da oferta da educação superior, gerando questionamentos em torno da qualidade da oferta desse ensino". Também afirma que a "prestação de contas (accountability) impulsiona a implantação de sistemas de avaliação da qualidade como forma de estabelecer a confiança nas IES, não somente por parte das sociedades, mas também de investidores financeiros" (SANTOS, 2019, p. 135). O autor ainda sinaliza a resposta para essas questões que corresponde a um modelo de "[...] avaliação participativa, em que estariam presentes os princípios: democracia direta, práxis política, participação dos sujeitos e a universidade como bem público" (SANTOS, 2019, p. 135-136).

Mancebo, Silva Junior, Oliveira (2018, p. 9) afirmam que as mudanças em curso implicam "[...] certamente uma análise das novas políticas que estão sendo gestadas, das alterações no padrão de organização, gestão e tomada de decisões nas IES, especialmente nas universidades públicas, e da perspectiva do direito à educação superior". Destacam os autores que as mudanças políticas estão sujeitadas às transformações econômicas mundiais e, ao mesmo tempo, a redução dos espaços de produção de conhecimento e saberes à lógica do mercado financeiro. A forte expansão da rede privada-mercantil de educação superior no Brasil, que remete à abertura de capitais das IES privadas aos investimentos na bolsa de valores, representa a maximização do lucro e a submissão gerencial das IES aos interesses dos grandes acionistas.

Obviamente que a problemática da Educação Superior perpassa por questões envolvendo o capitalismo avançado e também pelos protagonistas diretos das universidades (corpo docente, corpo discente, corpo técnico e colaboradores). Nesse âmbito, outros autores assinalam a hipótese desenvolvida por Leher (2015, p. 9), de que, “[...] sem os movimentos sociais antissistêmicos, a defesa de um lugar estratégico para a universidade pública, crítica e autônoma no projeto de nação permanecerá débil e, possivelmente, inviável".

De acordo com Lima e Machado (2016), a "era FHC" foi marcada pela evolução da matrícula na graduação da Educação Superior presencial, principalmente no setor privado, em detrimento da valorização do Ensino Superior público. O aumento da escolarização da população e do número de concluintes do Ensino Médio e as facilidades introduzidas pela flexibilização e regulação da Educação Superior são elementos que, segundo as autoras, ajudam a explicar o aumento de cerca de $130 \%$ no número de estudantes da Educação Superior entre 1990 e 2002 (LIMA; MACHADO, 2016).

O projeto de reforma universitária em curso ganharia corpo no governo do Partido dos Trabalhadores (PT), envolvendo questões como a qualidade dos cursos, a necessidade de diversidade e diferenciação do sistema, a resolução dos consistentes problemas envolvendo recursos, o aprimoramento dos mecanismos de regulação sobre a expansão dos sistemas e o peso do setor privado no seu conjunto. Desse modo, a política pública para a Educação Superior, no período de 2003 a 2010, pode ser interpretada como um conjunto sistêmico interdependente de sete pilares: autonomia, centralização do poder decisório, avaliação, 
formação de professores, flexibilização curricular, expansão e financiamento, que contribuíram para a intervenção do poder público a favor da expansão da Educação Superior (CARVALHO, 2014).

Nesse período, pode-se destacar a criação do Programa de Apoio aos Planos de Reestruturação e Expansão das Universidades Federais Brasileiras (REUNI), por meio do Decreto $\mathrm{n}^{\mathrm{o}} 6.096 / 2007$, da presidência da república. Esse programa integrou o Plano de Desenvolvimento da Educação (PDE), que instituiu o Plano de Metas Compromisso Todos pela Educação, por meio do Decreto $n^{0}$ 6.094/2007.

Decorrentemente, as ações desse período promoveram o aumento do número de universidades federais e a criação de novos campi das universidades existentes, ampliando a interiorização em áreas estratégicas, o aumento de cursos de graduação presencial, bem como a ampliação do número de vagas nesses cursos, além de elevar o número de matrículas, tanto no presencial como a distância, bem como dos programas de pós-graduação, que tiveram crescimento significativo.

A política para a Educação Superior do governo Dilma Rousseff (2011-2014) evidenciou alguns parâmetros a serem incorporados pelas universidades, tais como: inovação, empreendedorismo, competitividade, formação e atração de capital humano, mobilidade internacional, universidade como agente de desenvolvimento econômico e social, foco em áreas estratégicas/prioritárias de estudo e de pesquisa e internacionalização da Educação Superior (NEVES, 2012).

A partir do contexto apresentado, buscou-se identificar e compreender o arcabouço normativo que disciplina e operacionaliza a nova regulação das políticas de Educação Superior no país, observando os preceitos constitucionais e as diretrizes da educação nacional em relação à Educação Superior.

\section{A nova regulação da educação superior no Brasil}

Como anteriormente apresentado, a regulação da legislação educacional começa pela Carta Cidadã de 1988; observa-se que a LDBEN, no seu artigo $9^{\circ}$ - inciso IX-, quando trata da organização da educação nacional, atribui à União, de maneira exclusiva, o regramento de direito de "autorizar, reconhecer, credenciar, supervisionar e avaliar, respectivamente, os cursos das instituições de educação superior e os estabelecimentos do seu sistema de ensino".

Em 9 de maio de 2006, o Decreto $n^{\circ} 5.773$ foi promulgado observando as "funções de regulação, supervisão e avaliação da Instituição de Ensino Superior e cursos superiores de graduação e sequenciais no sistema federal de ensino". O Decreto $n^{\circ}$ 9.235/2017 revogou o Decreto $\mathrm{n}^{\mathrm{o}} 5.773 / 2006$, inscrevendo o entendimento à designação do tripé de funções de regulação, avaliação e supervisão.

Nesse cenário, reporta-se ao estudo de Barroso (2006, p. 44), que compreende a regulação nacional como o "modo como as autoridades públicas - Estado e administração exercem a coordenação, o controle e a influência sobre o sistema educativo, orientando através de normas, injunções e constrangimento o contexto da ação dos diferentes atores sociais e seus resultados". Entende-se que o conceito de regulação nacional instituído dentro do campo educacional está associado "à intervenção do Estado na condução das políticas públicas" (BARROSO, 2006, p. 50).

Dessa forma, pode-se extrair que o termo "regulação" perpassa por um conjunto de normas jurídicas, as quais estabelecem o controle da atividade privada pelo Estado, que, por sua vez, tem a obrigação de garantir a proteção do interesse público do cidadão aos serviços públicos. Nesse contexto, pode-se afirmar que o termo "regulação" está sendo compreendido como um conjunto de normas jurídicas que regula a funcionalidade do Ensino Superior brasileiro, o que significa dizer que todas as IES precisam obedecer a tais regras de direito, 
sob pena de ter seus atos invalidados e, nesta hipótese, sujeitas à aplicação das penalidades previstas na LDBEN, especialmente conforme consta no artigo 73 do Decreto $n^{\circ}$ 9.235/2017: “a) desativação de cursos e habilitações; b) intervenção; c) suspensão temporária de atribuições da autonomia; d) descredenciamento; e) redução de vagas autorizadas; f) suspensão temporária de ingresso de novos estudantes; ou g) suspensão temporária de oferta de cursos".

Extrai-se da normatização da regulamentação (Decreto $n^{0}$ 9.235/2017) que a regulação estabelece um conjunto de regras de conduta, bem como o controle de atividade privada pelo Estado, que, por seu turno, tem a responsabilidade da proteção do interesse público do indivíduo perante os serviços públicos. Assim, o termo "regulação" é utilizado para analisar a Educação Superior. Trata-se de um conjunto de leis, normas e determinações legais que rege a performance da Educação Superior, que deve ser observado por todas as instituições que tenham em suas ações esse nível de ensino, para que esse conjunto possa ser validado por meio do credenciamento institucional e serem reconhecidos seus cursos de graduação.

O Decreto $n^{\circ} 9.235 / 2017$ modificou, entre outros, os instrumentos de avaliação de cursos, estabelecendo papel indispensável ao avaliador, uma vez que esse componente do processo avaliativo irá elaborar, em comissão, relatórios do que foi averiguado in loco.

\section{Análise documental sistemática do Decreto $n^{0}$ 9.235/2017: em que se trata da regulação}

A atual legislação educacional brasileira, tal como a LDBEN, autoriza a União a centralizar a regulamentação e prover as condições de regulação pertinentes ao Ensino Superior. Considera-se, nesta pesquisa, que o Decreto $n^{\circ}$ 9.235/2017 retrata a "nova cara" da Educação Superior, na medida em que é recente sua promulgação, trazendo, de modo articulado e lógico, um conjunto de capítulos, seções e artigos que versam sobre o exercício das funções de regulação, supervisão e avaliação das IES e dos cursos superiores de graduação e de pós-graduação no Sistema Federal de Ensino (SFE).

Cada referência textual deve corresponder a uma referência completa na lista de referências ao final do corpo do texto. Confira antes de encaminhar o artigo se todas as citações estão corretas e se todas estão na lista de referências. As citações devem ser feitas na língua do artigo. No caso de documentos em outras línguas, o autor deve traduzir e indicar na referência (tradução nossa). Tipos de citação:

Quadro 1 - Sistematização do Decreto nº 9.235/2017

\begin{tabular}{|c|c|}
\hline Categoria & Conteúdos \\
\hline Título do documento & Decreto $\mathrm{n}^{\circ} 9.235$, de 15 dezembro de 2017 \\
\hline Ementa & $\begin{array}{l}\text { Dispõe sobre o exercício das funções de regulação, supervisão e } \\
\text { avaliação das instituições de Educação Superior e dos cursos superiores } \\
\text { de graduação e de pós-graduação no Sistema Federal de Ensino }\end{array}$ \\
\hline Chefe do Executivo & Michel Temer \\
\hline Natureza do texto & Decreto \\
\hline Local/Data de assinatura & Brasília, 15 de dezembro de 2017 \\
\hline Publicação & Diário Oficial da União, Seção 1, de 18 de dezembro de 2017 \\
\hline Referenda & Ministério da Educação \\
\hline Extensão do texto & 8 páginas \\
\hline Estrutura & $\begin{array}{l}\text { Capítulo } 1 \text { - Da Educação Superior no Sistema Federal de Ensino } \\
\text { (artigos } 1^{\circ} \text { ao } 7^{\circ} \text { ) } \\
\text { Capítulo II - Da regulação (artigos } 8^{\circ} \text { ao } 61 \text { ) } \\
\text { Capítulo III - Da supervisão (artigos } 62 \text { ao } 78 \text { ) } \\
\text { Capítulo IV - Da avaliação (artigos } 79 \text { ao } 89 \text { ) } \\
\text { Capítulo V - Disposições finais (artigos } 90 \text { ao 108) }\end{array}$ \\
\hline Artigos & 108 \\
\hline
\end{tabular}




\begin{tabular}{|c|c|}
\hline Assunto & $\begin{array}{l}\text { Dispositivos, normas, exercício, função, supervisão, avaliação, } \\
\text { instituição educacional, Ensino Superior, graduação, pós-graduação, } \\
\text { âmbito, instituição federal de ensino }\end{array}$ \\
\hline $\begin{array}{l}\text { Amparo legal e } \\
\text { normativo }\end{array}$ & $\begin{array}{l}\text { Artigo } 84 \text {, inciso IV, da Constituição Federal } \\
\text { Artigo } 9^{\circ} \text {, incisos VI, VIII e IX, e artigo } 46 \text { da Lei nº } 9.394 / 1996 \\
\text { Lei no } 9.784 \text {, de } 29 \text { de janeiro de } 1999 \\
\text { Lei } n^{\circ} 10.861 \text {, de } 14 \text { de abril de } 2004\end{array}$ \\
\hline Revogação & $\begin{array}{l}\text { Artigo } 15 \text { do Decreto } \mathrm{n}^{\circ} 6.861 \text {, de } 27 \text { de maio de } 2009 \\
\text { Decreto } \mathrm{n}^{\mathrm{o}} 5.773 \text {, de } 9 \text { de maio de } 2006 \\
\text { Decreto } \mathrm{n}^{\mathrm{o}} 5.786 \text {, de } 24 \text { de maio de } 2006 \\
\text { Decreto } \mathrm{n}^{\mathrm{o}} 6.303 \text {, de } 12 \text { de dezembro de } 2007 \\
\text { Decreto } \mathrm{n}^{\circ} 8.142 \text {, de } 21 \text { de novembro de } 2013 \\
\text { Decreto } \mathrm{n}^{\mathrm{o}} 8.754 \text {, de } 10 \text { de maio de } 2016\end{array}$ \\
\hline
\end{tabular}

Fonte: Elaborado pelos autores.

O Decreto $\mathrm{n}^{\mathrm{o}} 9.235$ foi assinado em 17 de dezembro de 2017, após o golpe parlamentar, pelo então chefe do Executivo, Michel Temer, sendo publicado no Diário Oficial da União $\mathrm{n}^{\circ} 241$ no dia seguinte. O documento possui oito páginas e 108 artigos, que se estruturam em cinco capítulos: Capítulo 1 - Da Educação Superior no Sistema Federal de Ensino (artigos $1^{\circ}$ ao $7^{\circ}$ ); Capítulo II - Da regulação (artigos $8^{\circ}$ ao 61); Capítulo III - Da supervisão (artigos 62 ao 78); Capítulo IV - Da avaliação (artigos 79 ao 89); Capítulo V Disposições finais (artigos 90 ao 108).

Tal instrumento se ampara legalmente na Constituição Federal (artigo 84, inciso IV), na LDBEN de 1996 (artigos 9º, incisos VI, VIII e IX, e 46) e nas Leis $n^{\circ}$ 9.784/1999 e $n^{\circ}$ 10.861/2004, sendo a primeira que regula o processo administrativo no âmbito da administração pública federal e a segunda que institui o Sistema Nacional de Avaliação da Educação Superior (SINAES).

O documento trata do novo marco regulatório, que aborda questões envolvendo a tramitação dos atos administrativos de autorização, reconhecimento ou renovação de reconhecimento de cursos superiores de forma sistemática e sequencial (BRASIL, 2017) e está dividido em três níveis de função, a saber, de regulação, supervisão e avaliação, das instituições de educação superior - IES e dos cursos superiores de graduação e de pósgraduação lato sensu, nas modalidades presencial e a distância, no sistema federal de ensino. (BRASIL, 2017, p. 2).

De acordo com o texto de lei, o Capítulo I, artigo $1^{\circ}$, parágrafo $1^{\circ}$, define que a regulação tem por finalidade "[...] promover a igualdade de condições de acesso, de garantir o padrão de qualidade das instituições e dos cursos e de estimular o pluralismo de ideias e de concepções pedagógicas", no que se refere a instituições tanto públicas quanto privadas de ensino (BRASIL, 2017, p. 2).

O parágrafo $2^{\circ}$ afirma que a supervisão "[...] será realizada por meio de ações preventivas ou corretivas, com vistas ao cumprimento das normas gerais da educação superior", visando garantir a "regularidade" e "[...] qualidade da oferta dos cursos de graduação e de pós-graduação lato sensu e das IES". Destaca-se o caráter preventivo previsto à supervisão, na medida em que anteriormente os processos de supervisão eram realizados com a finalidade de zelar pela conformidade da oferta de Educação Superior no SFE com a legislação aplicável, não considerando questões preventivas (BRASIL, 2017).

Já o parágrafo $3^{\circ}$ alude que a avaliação deverá ser realizada por meio do SINAES, com caráter formativo, e "[...] constituirá o referencial básico para os processos de regulação e de supervisão da educação superior, a fim de promover a melhoria de sua qualidade" (BRASIL, 2017, p. 2). O SINAES, por sua vez, tem o compromisso de cumprir seus objetivos e atender a suas finalidades constitucionais e legais, que compreendem os seguintes processos de avaliação: (I) avaliação interna das IES; (II) avaliação externa in loco das IES, realizada pelo Instituto Nacional de Estudos e Pesquisas Educacionais Anísio Teixeira (Inep); (III) avaliação 
dos cursos de graduação; e (IV) avaliação do desempenho acadêmico dos estudantes de cursos de graduação por meio do Exame Nacional de Desempenho dos Estudantes (ENADE) (BRASIL, 2014, 2017).

Desse modo, depreende-se que o SINAES assume uma função central na gestão e regulação da Educação Superior, visando propiciar maior qualidade à Educação Superior, por meio da adoção de processos de avaliação, em que existe a associação entre "a avaliação externa conduzida por pares à autoavaliação e somar informações do ENADE no modelo de larga escala", além de outros dados, como os fornecidos pelo Censo do Instituto Brasileiro de Geografia e Estatística (IBGE); com a convicção de que, dessa forma, poderia “[...] orientar a expansão da rede nacional de instituições de educação superior [...]", aumentando "[...] a eficácia institucional, postulando o cumprimento da responsabilidade social institucional com vistas a promover os valores democráticos" (HAAS, 2017, p. 117).

No artigo $3^{\circ}$ e subsequentes $\left(4^{\circ}\right.$ ao $\left.8^{\circ}\right)$, abordam-se as competências atribuídas ao MEC, ao Conselho Nacional de Educação (CNE), ao Instituto Nacional de Estudos e Pesquisas Educacionais Anísio Teixeira (Inep) e à Comissão Nacional de Avaliação da Educação Superior (Conaes), em relação às funções de regulação, supervisão e avaliação no SFE (Quadro 2).

Quadro 2 - Competências atribuídas às funções de regulação, supervisão e avaliação na Educação Superior, de acordo com o Decreto $\mathrm{n}^{\circ}$ 9.235/2017

\begin{tabular}{|c|c|}
\hline Órgão/Autoridade & Principais atribuições e competências \\
\hline $\begin{array}{l}\text { Ministro da Educação } \\
\left(\operatorname{artigo} 5^{\circ}\right)\end{array}$ & $\begin{array}{l}\text { - Homologar pareceres do CNE em pedidos de credenciamento, recredenciamento e } \\
\text { descredenciamento de IES. } \\
\text { - Homologar pareceres e propostas de atos normativos aprovados pelos instrumentos } \\
\text { de avaliação elaborados pelo Inep. } \\
\text { - Homologar as deliberações da Conaes. } \\
\text { - Expedir normas e instruções para a execução de leis, decretos e regulamentos. }\end{array}$ \\
\hline $\begin{array}{l}\text { Conselho Nacional de } \\
\text { Educação } \\
\left(\text { artigo } 6^{\circ}\right)\end{array}$ & $\begin{array}{l}\text { - Exercer atribuições normativas, deliberativas e de assessoramento } \\
\text { - Deliberar, por meio da Câmara de Educação Superior, sobre pedidos de } \\
\text { credenciamento, recredenciamento e descredenciamento } \\
\text { - Propor diretrizes e deliberar sobre a elaboração dos instrumentos de avaliação. } \\
\text { - Recomendar providências da Secretaria de Regulação e Supervisão da Educação } \\
\text { Superior do MEC. }\end{array}$ \\
\hline $\begin{array}{l}\text { Inep } \\
\left(\text { artigo } 7^{\circ}\right)\end{array}$ & $\begin{array}{l}\text { A) Conceber, planejar, coordenar e operacionalizar: } \\
\text { - As ações destinadas à avaliação de IES, de cursos de graduação e de escolas de } \\
\text { governo. } \\
\text { - O ENADE, os exames e as avaliações de estudantes de cursos de graduação. } \\
\text { B) Conceber, planejar, coordenar, operacionalizar e avaliar: } \\
\text { - Os indicadores referentes à Educação Superior } \\
\text { - A constituição e a manutenção de bancos de avaliadores e colaboradores } \\
\text { especializados. } \\
\text { C) Elaborar e submeter à aprovação do ministro de Estado da Educação os } \\
\text { instrumentos de avaliação externa in loco bem como seus respectivos indicadores } \\
\text { D) Presidir a Comissão Técnica de Acompanhamento da Avaliação (CTAA). } \\
\text { E) Planejar, coordenar, operacionalizar e avaliar as ações necessárias à consecução de } \\
\text { suas finalidades. }\end{array}$ \\
\hline $\begin{array}{l}\text { Conaes } \\
\left(\operatorname{artigo} 8^{\circ}\right)\end{array}$ & $\begin{array}{l}\text { - Propor e avaliar as dinâmicas, os procedimentos e os mecanismos de avaliação } \\
\text { institucional, de cursos e de desempenho dos estudantes. } \\
\text { - Estabelecer diretrizes para organização das comissões de avaliação } \\
\text { - Formular propostas para o desenvolvimento das IES } \\
\text { - Articular-se com os sistemas estaduais de ensino }\end{array}$ \\
\hline
\end{tabular}
Fonte: Brasil (2017).

Como previsto no Decreto $\mathrm{n}^{\mathrm{o}}$ 9.235, compete ao MEC, por meio da Secretaria de Regulação e Supervisão da Educação Superior (SERES), exercer as funções de regulação e supervisão da Educação Superior no âmbito do SFE (artigo $5^{\circ}$ ). Torna-se relevante destacar 
novamente o papel do CNE no âmbito desse decreto. O CNE foi instituído pela Lei $\mathrm{n}^{\mathbf{o}}$ 9.131/1995, que determina que esse conselho “[...] terá atribuições normativas, deliberativas e de assessoramento ao Ministro da Educação e do Desporto, de forma a assegurar a participação da sociedade no aperfeiçoamento da educação nacional".

Das instâncias que compõem o CNE, a Câmara de Educação Superior (CES) possui a atribuição de tomar as principais decisões que afetam as IES e os cursos de graduação, como processos de credenciamento, reconhecimento, autorização, recredenciamento de cursos, deliberação sobre as diretrizes curriculares e os instrumentos de avaliação, entre outras. São prerrogativas do CNE, segundo Carneiro e Novaes (2008, p. 720):

\begin{abstract}
No que tange às atribuições de regulação do CNE, a Lei $n^{\circ}$ 9.131/95 confere à Câmara de Educação Superior (CES), dentre outras funções, a de deliberar sobre os relatórios de reconhecimento de cursos, bem como sobre a autorização, o credenciamento e o recredenciamento periódico das IES, com base em relatórios e avaliações apresentados pelo MEC. Apresenta-se pela primeira vez, nesse momento, a intenção do governo em alinhar os processos de regulação e avaliação do ensino superior.
\end{abstract}

O Capítulo II, intitulado "Da regulação", está dividido em 12 seções, as quais compreendem: 1.1 - Atos autorizativos; 1.2 - Organizações acadêmicas; 1.3 - Credenciamento institucional; 1.4 - Recredenciamento institucional; 1.5 - Oferta de pós-graduação; 1.6 Campus fora de sede; 1.7 - Transferência de mantença; 1.8 - Autorização de cursos; 1.9 Reconhecimento e renovação de reconhecimento de cursos; 1.10 - Protocolo de compromisso; 1.11 - Encerramento da oferta de cursos e descredenciamento de instituições; e 1.12 Validade dos atos.

Para o efeito de ato autorizativo de regulação, de acordo com o artigo 10, existem dois tipos de atos autorizativos:

a) Os atos administrativos de credenciamento e recredenciamento de IES, que visam promover inicialmente o credenciamento da IES junto ao MEC e posteriormente manter de forma periódica a vinculação do ato por meio do recredenciamento.

b) Os atos administrativos de autorização, reconhecimento ou renovação de reconhecimento de cursos superiores pertinentes ao curso superior de graduação, quem corresponde à abertura (que é autorização de oferta de cursos vinculados ao credenciamento da IES), à continuidade dos cursos ofertados pela IES por meio dos procedimentos de reconhecimento (que é o registro de curso e suas condições necessárias à validação nacional dos diplomas) e renovação de reconhecimento.

Os artigos 11 e 12 definem que o MEC estabelecerá o calendário anual de abertura e conclusão de processos regulatórios, com o intuito de expedição dos atos autorizativos, e que as "[...] modificações do ato autorizativo serão processadas na forma de aditamento ao ato de credenciamento ou recredenciamento de IES, autorização, reconhecimento ou renovação de reconhecimento" (BRASIL, 2017, p 3). Os casos de arquivamento de processo ou decisão desfavorável poderão protocolar nova solicitação do ato relacionado ao mesmo pedido.

Observa-se que o caráter formativo da avaliação é considerado tal como destacado no parágrafo $3^{\circ}$ do artigo $1^{\circ}$. Sendo assim, vale destacar o artigo 13 desse decreto, por meio do qual se percebe que os pedidos de ato autorizativo serão decididos baseando-se em "conceitos e indicadores atribuídos ao conjunto e a cada uma das dimensões do SINAES" (BRASIL, 2017, p. 3). Já o artigo 14 define que as Instituições Federais de Educação Superior criadas por lei estão dispensadas do protocolo de ato autorizativo prévio pelo MEC.

Os artigos 16 e 17, que tratam "Das organizações acadêmicas" (Seção II), definem o credenciamento das faculdades, dos centros universitários e das universidades, sendo que as 
instituições privadas serão credenciadas inicialmente como faculdades (artigo 16, parágrafo $1^{\circ}$ ), podendo solicitar recredenciamento como centros universitários e universidades, desde que atendam às exigências previstas em lei.

$\mathrm{O}$ funcionamento das IES está associado à concessão do credenciamento pelo MEC (artigo 18). A Seção III, que trata do "Credenciamento institucional", descreve um conjunto de documentos e requisitos exigidos no ato do credenciamento (artigo 19). O "ato de credenciamento" de uma unidade e/o subunidade de IES deverá acompanhar "[...] o ato de autorização para a oferta, sendo aceito mediante análise e avaliação dos órgãos responsáveis " (BRASIL, 2017, p. 4).

A partir do recurso da imagem de um fluxograma (Figura 1), pode-se observar a direção ascendente do processo protocolar de credenciamento, tanto horizontal quanto verticalmente, que parte de uma IES, seguindo o calendário anexado anualmente pelo MEC. Em seguida, passa pela análise documental e pela avaliação externa, esta realizada pelo Inep. Tal processo resulta em pareceres emitidos pela SERES do MEC e pelo CNE.

Os requisitos protocolares de credenciamento, como estabelecem os artigos 20 e 21, correspondem à comprovação documental necessária e à apresentação pormenorizada do Plano de Desenvolvimento Institucional (PDI). O PDI visa integrar e nortear todo o processo de planejamento institucional, orientando a realização das ações e atividades propostas para a IES, que, por sua vez, expressa sua identidade no que diz respeito à sua filosofia de trabalho, à missão, à estrutura organizacional e às diretrizes administrativas e pedagógicas que orientam suas ações (RIBEIRO, 2015; SANTOS, 2019; SEGENREICH, 2018; MANCEBO et al., 2014; WEBER, 2010).

A discricionariedade em relação à qualificação, planos de carreira, critérios de seleção e regime de trabalho aparece associada à função estratégica de "desenvolvimento nacional, à inovação e à competitividade", visando à "articulação com o mercado de trabalho", destacando-se a dimensão economicista do modelo desenvolvimentista subjacente à política de regulação (DOURADO, 2009; HAAS, 2017). Trata-se, desse modo, de conceber uma regulação da educação que traga renovação, que seja capaz de remodelar as práticas educacionais vigentes até então, visando estabelecer um modelo pautado pela exigência de maior produtividade (DINIZ; GOERGEN, 2019), alinhado a mercantilização dos sistemas de educação e ensino transmundiais.

Paralelamente, o PDI deve atentar para as demandas de infraestrutura física e instalações acadêmicas (artigo 21, inciso VIII), o qual deverá indicar a existência de acervo bibliográfico físico, virtual (livros, periódicos acadêmicos e científicos, bases de dados e recursos multimídia); espaço físico para estudos e horário de funcionamento; laboratórios com instalações, equipamentos e recursos tecnológicos e sua relação com o projeto pedagógico-institucional dos cursos, capacidade e sustentabilidade financeiras, além de expor as "[...] formas de atualização e expansão de programas previstos e a descrição de inovações tecnológicas consideradas significativas" (BRASIL, 2017, p. 4).

No que diz respeito à oferta de $\mathrm{EaD}$ (artigo 21, inciso IX), o decreto estabelece que se devem especificar: a abrangência geográfica; a razão de polos de $\mathrm{EaD}$ previstos para a vigência do PDI; a infraestrutura física, tecnológica e de pessoal; as metodologias e tecnologias e sua correlação com os projetos pedagógicos dos cursos; e, por último, a previsão da capacidade de atendimento do público-alvo.

Após a análise documental e avaliação externa, a SERES é responsável pela emissão de um "parecer final", encaminhando o processo de credenciamento à Câmara de Educação Superior do CNE. O CNE pode deferir ou indeferir a solicitação de credenciamento quanto "às modalidades de oferta" e/ou "quanto aos cursos" (artigos 22 e 23). Os resultados, deferidos ou indeferidos, deverão ser homologados pelo ministro da Educação. De acordo com o parágrafo único do artigo 22, "O processo será encaminhado ao Ministro de Estado da 
Educação para homologação do parecer do CNE e publicação dos atos autorizativos de credenciamento" (BRASIL, 2017, p. 5).

Figura 1 - Fluxo do credenciamento e recredenciamento de IES

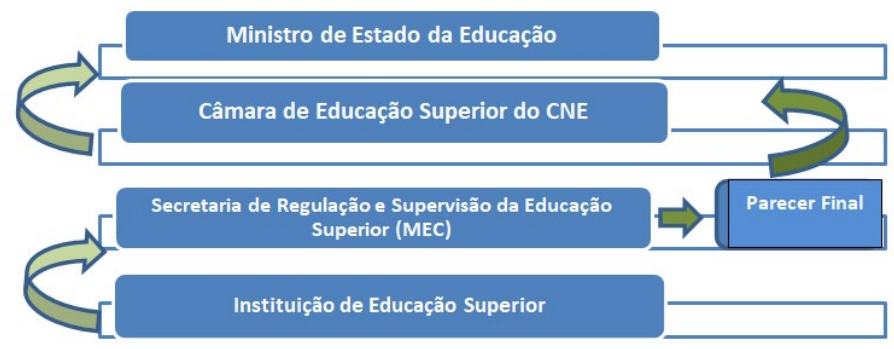

Fonte: Elaborado pelos autores.

No que tange ao objetivo deste estudo de analisar o Decreto $n^{0} 9.235 / 2017$, tendo por delimitação a função de regulação, das IES e dos cursos superiores de graduação, passa-se para a análise descritiva do processo de recredenciamento (Seção IV) e de autorização de novos cursos (Seção VIII). Por não serem o foco específico do objetivo desta pesquisa, os temas acerca da "oferta de pós-graduação" (Seção V), do "campus fora de sede" (Secção VI) e da "transferência de mantença" (Seção VII) não serão aprofundados neste trabalho.

O processo de recredenciamento está previsto nos artigos 25, 26 e 27. De acordo com o artigo 25, a IES deverá protocolar solicitação de recredenciamento junto à SERES do MEC. O pedido de alteração de organização acadêmica, como de uma faculdade para um centro universitário, ou o credenciamento de uma nova modalidade, como a $\mathrm{EaD}$, de instituições já credenciadas também obedecerão ao processo de recredenciamento, o qual exige atender a todos os requisitos processuais previstos nos artigos 19 e 20 . O parágrafo $5^{\circ}$ do artigo 25 enseja que qualquer irregularidade em relação à fazenda federal, à seguridade social e ao FGTS “[...] ensejará o sobrestamento dos processos regulatórios em trâmite", conforme os trâmites do Capítulo III do decreto, que estipula as medidas administrativas de supervisão (BRASIL, 2017, p. 5).

Pode-se destacar, a partir do artigo 26, o controle exigido pelo processo de recredenciamento, na medida em que a "[...] ausência de protocolo do pedido de recredenciamento no prazo devido caracterizará irregularidade administrativa", ficando a instituição "[...] impedida de solicitar aumento de vagas em cursos de graduação, de admitir novos estudantes e de criar novos cursos e polos de educação a distância", bem como "[...] sujeita a processo administrativo de supervisão" (BRASIL, 2017, p. 5).

$\mathrm{O}$ artigo 27 indica que, dependendo das condições, as faculdades poderão "[...] receber a atribuição de registrar seus próprios diplomas de graduação", conforme regulamento a ser editado pelo MEC. Essas instituições perderão tal atribuição caso tenham um "[...] conceito inferior em avaliação institucional subsequente", ou "[...] perda do reconhecimento do curso de pós-graduação stricto sensu"; ou ainda devido à "[...] ocorrência de penalização em processo administrativo de supervisão” (BRASIL, 2017, p. 5). O recredenciamento de organização acadêmica como centro universitário ou universidade dependerá da "manutenção" dos critérios exigidos para o credenciamento do respectivo nível de organização acadêmica (artigo 28).

A autorização de cursos prevista nos artigos 39 ao 44 estabelece que somente as faculdades dependem de autorização prévia do MEC para a oferta de novos cursos (artigo 39). Os centros universitários e as universidades independem dessa autorização (artigo 40), embora devam informar, no prazo de 60 dias a partir do "ato de criação do curso", à SERES. 
De acordo com o Decreto ${ }^{0}$ 9.235/2017, recomenda-se que o Projeto Pedagógico de Curso (PPC) esteja articulado e alinhado ao Projeto Pedagógico Institucional (PPI), que, por sua vez, deverá estar com o PDI. Assim, o referido decreto também orienta, em seu artigo 43, quanto aos elementos obrigatórios que deverão constar no próprio PPC.

O pedido de autorização de curso será instruído com os seguintes documentos:

[...] II - projeto pedagógico do curso, que informará o número de vagas, os turnos, a carga horária, o programa do curso, as metodologias, as tecnologias e os materiais didáticos, os recursos tecnológicos e os demais elementos acadêmicos pertinentes, incluindo a consonância da infraestrutura física, tecnológica e de pessoal dos polos de educação a distância do curso, quando for o caso [...]. (BRASIL, 2017, p. 12).

O PPC é o instrumento de concepção de ensino e aprendizagem de um curso, possui características de um projeto, no qual devem ser definidos alguns componentes, tais como: 1. Concepção do curso; 2. Estrutura do curso: currículo, corpo docente, corpo técnico administrativo e infraestrutura; 3. Procedimentos de avaliação dos processos de ensino e aprendizagem e do curso; 4. Instrumentos normativos de apoio (composição do colegiado, procedimentos de estágio, trabalho de conclusão de curso, dentre outros.

Conforme o artigo 43, a solicitação de autorização de curso exige os seguintes documentos: taxa de avaliação externa; PPC (com número de vagas, carga horária, programa do curso, metodologias, tecnologias e materiais didáticos, recursos tecnológicos, etc.); corpo discente e de tutores; e comprovação de disponibilidade do imóvel e demais condições infraestruturais.

Em relação ao reconhecimento e à renovação de reconhecimento de cursos de que trata o artigo 45 da Seção IX, observa-se que o reconhecimento e o registro de curso "são condições necessárias à validade nacional dos diplomas". O artigo 46 estabelece que a instituição deve protocolar o "[...] pedido de reconhecimento de curso no período compreendido entre cinquenta por cento do prazo previsto para integralização de sua carga horária e setenta e cinco por cento desse prazo, observado o calendário definido pelo Ministério da Educação" (BRASIL, 2017, p. 6).

De modo contrário, conforme definido no artigo 48, a ausência de protocolação de reconhecimento incorre em "[...] irregularidade administrativa e a instituição ficará impedida de solicitar aumento de vagas e de admitir novos estudantes no curso, sujeita, ainda, a processo administrativo de supervisão" (BRASIL, 2017, p. 6), sendo que tal processo também depende de aprovação e decisão da SERES do MEC (artigo 49). A documentação exigida para o reconhecimento e renovação é a mesma prevista no artigo 43.

A SERES detém o poder discricionário de deferir o pedido de reconhecimento ou renovação de reconhecimento de curso (artigo 52), de acordo com os critérios de análise documental e o mérito do pleito. Ela poderá solicitar um protocolo de compromisso, visando adequar e superar possíveis fragilidades identificadas no processo de renovação e/ou reconhecimento.

O protocolo de compromisso, previsto nos artigos 53 e 54 da Seção X, ocorre quando da "[...] obtenção de conceitos insatisfatórios no conjunto ou em cada uma das dimensões do relatório de avaliação externa in loco realizada pelo Inep, considerados os procedimentos e os instrumentos diversificados de avaliação do SINAES" (BRASIL, 2017, p. 6), seja nos processos de processos de recredenciamento, reconhecimento e renovação de reconhecimento de cursos. 
Ao término do prazo ou "vigência" do protocolo de compromisso, a IES será submetida à avaliação externa, visando verificar o seu cumprimento e a superação das fragilidades detectadas (artigo 55).

Os artigos 56 e 57, que encerram o tema regulação do referido decreto, descrevem o elemento sancionador para as IES que não cumprirem o protocolo de compromisso, e com as Seções XI e XII, as quais discorrem acerca do "encerramento da oferta de cursos e descredenciamento de instituições" e da "validade dos atos", respectivamente.

O descredenciamento de IES, conforme descrito no artigo 57, pode ocorrer em decorrência da solicitação da própria instituição ou decorrente de procedimento sancionador aplicado por instâncias de supervisão. No caso de IES privadas, a sanção impõe à mantenedora a "vedação de ingresso de novos estudantes"; a entrega de registros e documentos acadêmicos aos estudantes; e a "oferta final de disciplinas e transferência de estudantes", dependendo da necessidade.

Embora o objetivo deste artigo tenha se concentrado no dispositivo de regulação que trata o Decreto $\mathrm{n}^{\mathrm{o}}$ 9.235, pode-se brevemente apontar que o mesmo versa sobre o ato autorizativo de supervisão, em seu Capítulo II, e ao ato de avaliação, no Capítulo IV. A supervisão está prevista por meio de ações preventivas ou corretivas, com vistas ao cumprimento das normas gerais da educação superior, a fim de zelar pela regularidade e pela qualidade da oferta dos cursos de graduação e de pós-graduação lato sensu e das IES que os ofertam. (BRASIL, 2017, p. 7). O artigo 63 explicita que o "processo administrativo de supervisão" deve ser instaurado quando da constatação de "deficiências ou irregularidades" e podem ser consideradas três fases: a) procedimento preparatório; b) procedimento saneador; e c) procedimento sancionador. É relevante considerar que, em face da ameaça ao interesse público e ao interesse dos estudantes, no artigo 64, os atos de supervisão deverão "resguardar os interesses dos estudantes".

No que se refere a Avaliação prevista no decreto, tema que extrapola este artigo, podese de modo breve informar que a avaliação das IES está composta por duas seções, a saber: "Da avaliação das instituições de Educação Superior e dos cursos superiores de graduação e pós-graduação" (Seção I) e "Da avaliação do desempenho acadêmico dos estudantes de cursos de graduação por meio do ENADE”. Ele envolve 11 artigos (artigos 79 ao 89), tendo como centro articulador do processo de avaliação o SINAES, tal como apresentado acima.

Constata-se, assim, como o SINAES está articulado aos processos de "[...] regulação e supervisão da educação superior, [...] o credenciamento e a renovação de credenciamento de instituições de educação superior, a autorização, o reconhecimento e a renovação de reconhecimento de cursos de graduação" (BRASIL, 2004, p. 1).

É importante destacar que a articulação entre avaliação e controle das IES públicas e privadas por meio da regulação proposta pelo Decreto 9.235 vem ocorrendo em um contexto de forte privatização da educação superior, cerceamento democrático e precarização das Universidades Públicas, ao mesmo tempo e que há a "expansão do setor privado mercantil e internacionalizado" (MANCEBO et al, 2018, p. 8), promovendo maior liberdade às empresas educacionais. Tal fato mostra que, o sistema de regulação e regulamentação imposto pela atual política educacional se coaduna com a mercantilização internacional da educação, em que os mecanismos de Estado estão votados para o gerenciamento e monitoramento, visando maior eficácia, qualidade e eficiência.

\section{Considerações Finais}

Em resumo, o Decreto $n^{0}$ 9.235/2017 dispõe sobre o marco regulatório da Educação Superior, visando sobretudo à promoção da "[...] igualdade de condições de acesso, de garantir o padrão de qualidade das instituições e dos cursos e de estimular o pluralismo de 
ideias e de concepções pedagógicas e a coexistência de instituições públicas e privadas de ensino" (BRASIL, 2017, p. 2). É a partir desse dispositivo legal que se trata a tramitação do exercício das funções de regulação - por intermédio de atos autorizativos de funcionamento de IES e de oferta de cursos superiores de graduação e pós-graduação lato sensu; supervisão realizada por meio de ações preventivas e corretivas; e avaliação - realizada por meio do SINAES, com caráter formativo, constituindo-se como base para os processos de regulação e supervisão das IES - dos respectivos cursos ofertados, sejam de graduação ou pós-graduação lato sensu.

Verhine (2015) enfatiza que a articulação entre os processos de regulação e avaliação são fontes subsidiárias para a retroalimentação das decisões no âmbito da regulação, para que possam tratar da autorização, do reconhecimento e da renovação de reconhecimento de cursos superiores, bem como do credenciamento e do recredenciamento de IES. Desse modo, aponta o especialista, os dez primeiros anos do SINAES estabeleceram algumas assertivas a respeito da relação entre a avaliação e a regulação da Educação Superior. Primeiro, por que autor considera a regulação como uma política de governo, na medida em que atribui ajustes em função de políticas públicas, no sentido de adequar conflitos sociais, mitigando garantias de padrões de qualidade mínima. Segundo, por que entende a avaliação prevista no SINAES como uma política de Estado, na medida em que está amparada em critérios técnicos protegidos da interferência da natureza política ou imediatista.

Entretanto, ainda seria preciso questionar qual política de Estado se refere Verhine, o Estado-Mínimo dos neoconservadores e neoliberais, ou o Estado de Bem-estar Social, tal como foi postulado na Constituição de 1988? A expansão da educação superior no âmbito do mercado revela que tal modelo de regulação segue a indução do plano macroeconômico mundial, em que se observa o modelo de acumulação flexível e o desenvolvimento econômico e financeiro. Concomitantemente, a educação ganharia centralidade com a globalização e as reformas setoriais, assumindo uma triplicidade estratégica: econômica, científica e cultural (PASSONE, 2014).

A partir das ações do Ministério da Administração Federal e da Reforma do Estado MARE -, comandado pelo então ministro Luís Carlos Bresser Pereira, elaboram-se a proposta do Plano Diretor da Reforma do Estado. A Emenda Constitucional promulgada em 1998, com a proposta de modernização e reforma administrativa do aparato estatal terminou por dividir em dois tipos as atividades estatais: a) as "atividades exclusivas do Estado", tais como legislar, tributar, regular, fiscalizar e formular políticas, enquanto ações do "núcleo estratégico" do Estado; e, b) as "atividades não-exclusivas" do Estado, subdividas em "serviços competitivos" e "atividades auxiliares ou de apoio".

Nesse sentido, a avaliação e a regulação estariam previstas como um dos principais enfoques da reforma do Estado, a partir do modelo gerencial empresarial. Tal modelo trouxe para o primeiro plano o debate sobre o gasto público e a qualidade dos serviços prestados mediante a administração pública, relegando para um segundo plano questões substanciais, tais como os conflitos oriundos das sociedades democráticas, a garantia de direitos de cidadania, os pleitos por equidade e justiça social, acarretando na redução das diferenças simbólicas de que tratam os projetos políticos em termos societários.

Nesse sentido, o Decreto 9.235 pode ser compreendido no amplo campo gerencialista que se iniciou com o movimento de reformas educacionais dos anos 1990 e acompanhou o processo de "modernização" administrativa estatal e a conjuntura político-econômica globalizada, representando um conjunto de ações de flexibilização, desestabilização, publicização e privatização, promovidas através das novas regulações administrativas do Estado brasileiro. Assim, a promoção de mecanismos de mercado no interior do espaço estatal, na linha do pragmatismo e dos princípios da New Public Management anglo-saxão, isto é, enquanto "extensão das ideias da gestão privada ao setor público, subordinaria os 
direitos sociais e de cidadania à lógica do mercado, em que prevalecem a competição e a produtividade, normalmente propagadas por meio de discursos sobre eficácia, eficiência e qualidade.

\section{Referências}

BARROSO, J. O Estado, a educação e a regulação das políticas públicas. Educ. Soc., Campinas, v. 26, n. 92, p. 725-751, Oct. 2005.

BRASIL. Decreto no 5.773 , de 9 de maio de 2006. Dispõe sobre o exercício das funções de regulação, supervisão e avaliação de instituições de Educação Superior e cursos superiores de graduação e seqüenciais no Sistema Federal de Ensino. Diário Oficial [da] República Federativa do Brasil, Poder Executivo, Brasília, DF, 10 maio 2006.

BRASIL. Decreto n ${ }^{0}$ 6.096, de 24 de abril de 2007. Institui o Programa de Apoio a Planos de Reestruturação e Expansão das Universidades Federais - Reuni. Diário Oficial [da] República Federativa do Brasil, Poder Executivo, Brasília, DF, 25 abr. 2007.

BRASIL. [Lei Darcy Ribeiro (1996)]. LDB: Lei de Diretrizes e Bases da Educação Nacional: Lei $\mathrm{n}^{\circ}$ 9.394, de 20 de dezembro de 1996, que estabelece as Diretrizes e Bases da Educação Nacional. 9. ed. Brasília, DF: Câmara dos Deputados, 2014.

BRASIL. Lei $n^{\circ} 13.005$, de 25 junho de 2014. Aprova o Plano Nacional de Educação - PNE e dá outras providências. Diário Oficial [da] República Federativa do Brasil, Poder Executivo, Brasília, DF, 26 jun. 2014.

BRASIL. Lei $n^{\circ} 10.260$, de 12 de julho de 2001. Dispõe sobre o Fundo de Financiamento ao Estudante do Ensino Superior e dá outras providências. Diário Oficial [da] República Federativa do Brasil, Poder Executivo, Brasília, DF, 13 jul. 2001.

BRASIL. Lei $n^{\circ}$ 10.861, de 14 de abril de 2004. Institui o Sistema Nacional de Avaliação da Educação Superior - SINAES e dá outras providências. Diário Oficial [da] República Federativa do Brasil, Poder Executivo, Brasília, DF, 15 abr. 2004.

BRASIL. Lei $\mathrm{n}^{\circ} 11.096$, de 13 de janeiro de 2005. Institui o Programa Universidade para Todos - Prouni, regula a atuação de entidades beneficentes de assistência social no ensino superior; altera a Lei $\mathrm{n}^{\mathrm{o}} 10.891$, de 9 de julho de 2004, e dá outras providências. Diário Oficial [da] República Federativa do Brasil, Poder Executivo, Brasília, DF, 14 jan. 2005.

BRASIL. Medida Provisória ${ }^{\circ}$ 147, de 15 de dezembro de 2003. Institui o Sistema Nacional de Avaliação e Progresso do Ensino Superior e dispõe sobre a avaliação do ensino superior. Diário Oficial [da] República Federativa do Brasil, Poder Executivo, Brasília, DF, 16 dez. 2003.

BRASIL. Lei $n^{\circ}$ 9.131, de 24 de novembro de 1995. Altera dispositivos da Lei $n^{\circ} 4.024$, de 20 de dezembro de 1961, e dá outras providências. Diário Oficial [da] República Federativa do Brasil, Poder Executivo, Brasília, DF, 25 nov. 1995.

BRASIL. Constituição de 1988. Constituição da República Federativa do Brasil. Diário Oficial [da] República Federativa do Brasil, Poder Executivo, Brasília, DF, 5 out. 1988.

BRASIL. Decreto $n^{\circ} 9.235$, de 15 de dezembro de 2017. Dispõe sobre o exercício das funções de regulação, supervisão e avaliação das instituições de educação superior e dos cursos superiores de graduação e de pós-graduação no Sistema Federal de Ensino. Diário Oficial [da] República Federativa do Brasil, Poder Executivo, Brasília, DF, 16 dez. 2017. 
BRASIL. Decreto-Lei $\mathrm{n}^{\circ}$ 464, de 11 de fevereiro de 1969. Estabelece normas complementares à Lei $\mathrm{n}^{\mathrm{o}} 5.540$, de 28 de novembro de 1968, e dá outras providências. Especial de Desempenho Institucional por Perícia Médica em Benefícios por Incapacidade. Diário Oficial [da] República Federativa do Brasil, Poder Executivo, Brasília, DF, 11 fev. 1969.

BRASIL. Lei $\mathrm{n}^{\mathrm{o}}$ 4.024, de 20 de dezembro de 1961. Fixa as Diretrizes e as Bases para o Ensino de $1^{\circ}$ e $2^{\circ}$ graus, e dá outras providências. Diário Oficial [da] República Federativa do Brasil, Poder Executivo, Brasília, DF, 27 dez. 1961.

BRASIL. Lei $\mathrm{n}^{\mathrm{o}} 5.540$, de 28 de novembro de 1968. Fixa normas de organização e funcionamento do ensino superior e sua articulação com a escola média, e dá outras providências. Diário Oficial [da] República Federativa do Brasil, Poder Executivo, Brasília, DF, 28 nov. 1968.

CARNEIRO, B. P. B.; NOVAES, I. L. As comissões próprias de avaliação frente ao processo de regulação do Ensino Superior privado. Avaliação, Campinas, v. 13, n. 3, p. 713-732, 2008.

CARVAlHO, C. H. A. Política para a Educação Superior no governo Lula: expansão e financiamento. Revista do Instituto de Estudos Brasileiros, São Paulo, n. 58, p. 209-244, 2014.

CELLARD, A. A análise documental. In: POUPART, J. et al. (org.). A pesquisa qualitativa: enfoques epistemológicos e metodológicos. Petrópolis: Vozes, 2012. p. 295-316.

CUNHA, L. A. O Ensino Superior no octênio FHC. Educação \& Sociedade, Campinas, v. 24, n. 82, p. 37-61, 2003.

DAVIS, N. O financiamento público às escolas privadas. Revista Universidade e Sociedade, Brasília, DF, v. 11, n. 27, p. 74-91, 2002.

DEMO, P. A nova LDB: ranços e avanços. Campinas: Papirus, 1997.

DIAS SOBRINHO, J. Avaliação e transformações da Educação Superior brasileira (19952009): do Provão ao Sinaes. Avaliação, Sorocaba, v. 15, n. 1, p. 195-224, 2010.

DINIZ, R. V.; GOERGEN, P. L. Educação Superior no Brasil: panorama da contemporaneidade. Avaliação, Sorocaba, p. 573-593, v. 24. n. 3, 2019.

DOURADO, L. F. (org.). Políticas e gestão da educação no Brasil: novos marcos regulatórios. São Paulo: Xamã, 2009.

FÁVERO, M. L. A. A universidade no Brasil: das origens à Reforma Universitária de 1968. Educar, Curitiba, n. 28, p. 17-36, 2006.

HAAS, C. M. Educação Superior no Brasil e os condicionamentos às políticas nacionais: impactos da regulação transnacional na gestão universitária. Universidade Federal de São Carlos, Brasil. Laplage em Revista, Sorocaba, v. 3, n. 3, p. 115-132, 2017.

LEHER, R. Movimentos sociais, padrão de acumulação e crise da universidade. In: REUNIÃO NACIONAL DA ANPED, 37., 2015. Anais [...]. . Florianópolis, SC, 2015.

LIMA, E. E.; MACHADO, L. R. S. Reuni e expansão universitária na UFMG de 2008 a 2012. Educação \& Realidade, Porto Alegre, v. 41, n. 2, p. 383-406, 2016.

MANCEBO, D.; SILVA JUNIOR, J. R.; OLIVEIRA, J. F. Políticas, gestão e direito à Educação Superior: novos modos de regulação e tendências em construção. Acta Scientiarum: Education, Paraná, v. 40, n. 1, p. 1-11, 2018. 
NEVES, C. E. B. Ensino Superior no Brasil: expansão, diversificação e inclusão. In: CONGRESSO DA LASA, 30., 2012, San Francisco. Anais [...]. San Francisco: Lasa, 2012.

PASSONE, E. F. K. Incentivos monetários para professores: avaliação, gestão e responsabilização na educação básica. Cad. Pesqui., São Paulo , v. 44, n. 152, p. 424-448, 2014 .

PASSONE, E. F. K. Psicanálise e Educação: o discurso capitalista no campo educacional. ETD - Educação Temática Digital, Campinas, SP, v. 15, n. 3, p. 407-424, 2013.

PEREIRA, T. I.; SILVA, L F. C. As políticas públicas do Ensino Superior do governo Lula: expansão ou democratização. Revista Debates, Porto Alegre, v. 4, n. 2, p. 10-31, 2010.

SAVIANI, D. A nova Lei da Educação: trajetória, limites e perspectivas. 8. ed. Campinas: Autores Associados, 2003.

SANTOS, M. G. Trilhas da avaliação da Educação Superior no brasil: os (des)caminhos em direção ao Sinaes. Espaço Pedagógico, Passo Fundo, v. 26, n. 1, p. 117-138, 2019.

SEGENREICH, S. C. D. Regulação/avaliação da Educação Superior a distância: multiplicidade de atores institucionais, labirinto de atos oficiais e avaliação regulatória. Revista Brasileira de Política e Administração da Educação, Brasília, DF, v. 34, n. 1, p. 99-119, 2018.

SILVA JUNIOR, A. et al. Políticas públicas para a educação superior: a avaliação, a regulação e a supervisão de instituições de ensino superior privadas em debate. Ensaio: Avaliação e Políticas Públicas em Educação, Rio de Janeiro, v. 22, n. 82, p. 215-240, 2014.

SGUISSARDI, V. Regulação estatal e desafios da expansão mercantil da Educação Superior. Educação \& Sociedade, Campinas, v. 34, n. 124, p. 943-960, 2013.

SOUZA, P. N. P.; SILVA, E. B. Como entender e aplicar a nova LDB. São Paulo: Pioneira Thompson Learning, 2001.

RIBEIRO, J. L. L. S. Sinaes: o que aprendemos acerca do modelo adotado para avaliação do Ensino Superior no Brasil. Avaliação, Campinas, v. 20, n. 1, p. 143-161, 2015.

VERHINE, R. E. Avaliação e regulação da Educação Superior: uma análise a partir dos primeiros 10 anos do Sinaes. Avaliação, Campinas, v. 20, n. 3, p. 603-619, 2015.

WEBER. S. Avaliação e regulação da Educação Superior: conquistas e impasses. Educação e Sociedade, Campinas, v. 31, n. 113, p. 1247-1269, 2010. 